\title{
Dengue virus-1 NS5 genetic variant associated with a severe clinical infection: Possible reduction of the innate immune response by inhibition of interferon type 1 and the Janus kinase-signal transducer and activator of transcription signaling pathway
}

\author{
IVÁN DELGADO-ENCISO ${ }^{1,2 *}$, URIEL A. LÓPEZ-LEMUS ${ }^{1,3,4^{*}}$, JOSE A. VALCARCEL-GAMIÑO ${ }^{5}$, \\ IRAM P. RODRIGUEZ-SANCHEZ ${ }^{6}$, SALVADOR VALLE-REYES ${ }^{1,3}$, \\ MARGARITA L. MARTINEZ-FIERRO ${ }^{7}$, VALERY MELNIKOV ${ }^{1}$, JOSÉ GUZMÁN-ESQUIVEL ${ }^{8}$, \\ FELIPE VACA-PANIAGUA ${ }^{9}$, LAURA L. VALDEZ-VELAZQUEZ ${ }^{5}$, LUZ M. BALTAZAR-RODRIGUEZ ${ }^{1}$, \\ ALEJANDRO D. SORIANO-HERNANDEZ ${ }^{1,2}$, BRENDA PAZ-MICHEL ${ }^{10}$ and FRANCISCO ESPINOZA-GÓMEZ ${ }^{1}$ \\ ${ }^{1}$ Department of Public Health, School of Medicine, University of Colima, Colima, Colima 28030; \\ ${ }^{2}$ Department of Research, Cancerology State Institute, Colima State Health Services, Colima, Colima 28000; \\ ${ }^{3}$ Department of Health Sciences, Center for Biodefense and Global Infectious Diseases; ${ }^{4}$ Scientific Research Team, \\ Gene Scientific Laboratory, Colima, Colima 28017; ${ }^{5}$ Department of Chemical Sciences, School of Chemical Sciences, \\ University of Colima, Coquimatlán, Colima $28400 ;{ }^{6}$ Genetics Department, School of Medicine, \\ Nuevo León Autonomous University, Monterrey, Nuevo León 64460; ${ }^{7}$ Molecular Medicine Laboratory, \\ Academic Unit of Human Medicine and Health Sciences, Zacatecas Autonomous University, Zacatecas, Zacatecas 98160; \\ ${ }^{8}$ Department of Research, Mexican Social Security Institute, Villa de Alvarez, Colima 28983; \\ ${ }^{9}$ Biomedicine Unit, School of Graduate Studies-Iztacala, National Autonomous University of Mexico, \\ Mexico City, State of Mexico 04510; ${ }^{10}$ Esteripharma Mexico, Mexico City, State of Mexico 03100, Mexico
}

Received October 12,2017; Accepted January 4, 2018

DOI: $10.3892 /$ ijmm.2018.3395

\begin{abstract}
Dengue virus (DENV) is currently considered as one of the most important mosquito-borne viral pathogens affecting humans. Genetic variations in viruses are likely to be a condition for more effective evasion of the immune system and resulting in severe clinical consequences. The DENV-1 NS5 gene was sequenced to establish whether during an epidemic burst there were genetic variations of the virus and whether any variant was associated (through a case-control design) with severe clinical behavior. A total of 31 patients positive for DENV-1 were enrolled. Among the nucleotide
\end{abstract}

Correspondence to: Dr Francisco Espinoza-Gómez, Department of Public Health, School of Medicine, University of Colima, 333 University Avenue, Colonia Las Víboras, Colima, Colima 28030, Mexico

E-mail: fespin@ucol.mx

${ }^{*}$ Contributed equally

Key words: dengue, risk factor, severity, infection, genetic variant, interferon, signal transducer and activator of transcription factor-1, Janus kinase-1 differences between the sequences, only two generated amino acid changes. The variants $124 \mathrm{Met} / 166 \mathrm{Ser}$ (amino acid positions according to the report GenBank AJL35015.1), were associated with a severe clinical course of the disease. Via in silico tests, it was identified that the variations generate changes in the protein probably affecting the function of type-1 interferon, either at the level of its receptor or by interfering with the Janus kinase-signal transducer and activator of transcription signaling pathway.

\section{Introduction}

Dengue is currently the most important mosquito-borne viral pathogen that affects humans. Estimates indicate that 3 billion people live in tropical and subtropical regions where they are at risk of infection. There are reports of $\sim 96$ million symptomatic episodes and $\sim 20,000$ cases of mortality each year (1). Dengue ranges clinically from asymptomatic or self-limiting non-severe dengue (with or without warning symptoms) to severe dengue, which is characterized variously by severe plasma leakage, severe bleeding or severe organ involvement (2). The clinical presentation is difficult to predict, although the presence of warning signs in the first day warrant strict observation and medical intervention. The triage of patients who are likely to require intensive care during hospitalization would reduce the 
risk of mortality. The factors proposed for increased risk of severe clinical manifestations remain poorly characterized. Age, sex, social status, genetic background, sickle cell anemia, uremia, bronchial asthma, allergies, hypertension, chronic renal failure, concurrent bacterial infections, and diabetes mellitus may adversely influence the clinical presentation of an infection (3). The identification of patients for intensive monitoring in a well-resourced high-dependency unit with medical and nursing staff trained in dengue and critical care management may improve clinical outcomes (2).

Host factors and the genetic variability of the virus are other crucial factors. Dengue virus (DENV) is a single positive RNA filament, belonging to the genus Flavivirus (FV) and constitutes four large groups or serotypes that infect humans. These are classified as DENV-1, -2, -3 and -4. Despite the remarkable genetic similarity between the four serotypes, these viruses have epidemiological variability and specific immunological response (3).

Like all FVs, DENV has a high rate of genetic diversity, due to recombination and mutations at selective pressures in its genome (2). For this reason, each serotype has at least five genetic variants that are sufficiently different to explain changing clinical and epidemiological behavior (4). Traditionally, severe forms of dengue, including dengue hemorrhagic fever, are due to the phenomenon known as antibody dependent enhancement, in which the presence of antibodies against a determined serotype enhances viral replication within infected cells in a second infection with a different serotype (5). However, it has been demonstrated that certain strains of DENV are naturally aggressive and are able to generate severe dengue from the first infection (6).

The prognosis of DENV infection is determined by a balance between the rate of viral replication and the efficiency of the immune system for viremia clearance (7). Innate immunity is crucial at the beginning of infection and includes interferon (IFN)- $\gamma$ action, cytokine-mediated signaling, chemotaxis, and complement activity, among others. The processes triggered by these molecules are activated at days $0-1$ following DENV infection and decline 3-4 days thereafter. The upregulation of this early innate immune response generates a reduction in DENV replication during days 0-3 (6,7). Deficiencies in specific and non-specific immune-driven antiviral responses result in unrestricted DENV replication and dissemination in the host, with the possible appearance of severe clinical manifestations (7). Comorbidities that may lead to immunologic deficiencies in the host, such as diabetes, are risk factors for severe dengue (3). However, viral genetic variations may also effectively evade the immune response with severe clinical consequences. As such, the genetic variations of dengue and its association with clinical manifestations are an interesting topic of study with scarce evidence.

A recent study has suggested that a rapid pattern of mutations in DENV-1 is possible within an epidemic (evolutionary process in situ) (8), although it is not known whether this may induce a change in the virus transmission pattern and its pathogenicity. In order to examine the genetic variability of DENV during an epidemic, the NS5 protein gene was examined. This gene, with low variability, was sequenced to establish whether during an epidemic there were genetic variations of the virus that may be differentiated phylogenetically and whether any variant was associated (through a case-control design) with severe clinical behavior. In addition, in silico, the possible consequences of these genetic variations generated in the NS5 viral protein and their possible impact on the innate immune response were evaluated.

\section{Patients and methods}

Patients. The present study was conducted from June 2007-December 2008 in patients with acute fever who consulted at the Public Health Services of the State of Colima (Colima, Mexico; 632,000 habitants). Antecubital venous blood samples were collected from 462 febrile patients (male:female, 228:234; age range, 6-80 years old) who attended medical units. The samples were collected under aseptic conditions with a Vacutainer tube with EDTA maintained at $4^{\circ} \mathrm{C}$ for a maximum of $6 \mathrm{~h}$. The serum was separated and stored at $-70^{\circ} \mathrm{C}$ until processing. The inclusion criterion was the presence of fever with an evolution between 2 and 7 days with a follow up on diagnosis, and the medical management received. Exclusion criteria included patients from other locations outside the State of Colima, age $<5$ or $>80$ years, a frank septic focus (abscesses and pneumonia), immunosuppressive states (diabetes, HIV/AIDS and chemotherapy) or fever onset during hospital stay. First-contact physicians evaluated all patients and the intake was made prior to deciding their hospitalization or discharge. Sequential convenience sampling was used to obtain a constant proportion of cases by each participating medical center throughout the study.

Patient data were registered, including age, sex, place of residence, time of evolution with fever, initial presumptive diagnosis and final diagnosis recorded by the medical staff of each unit. In cases that required hospitalization, their diagnosis of discharge was recorded. Patients participated voluntarily in the present study and signed statements of informed consent to use their blood samples, following the guidelines of the project as approved by the Institutional Ethics Committee of the Department of Health (Colima, Mexico).

Sample processing. Total RNA was extracted from blood samples using an RNeasy mini kit (Qiagen, Inc., Valencia, CA, USA). RNA samples were treated with DNase I (Invitrogen; Thermo Fisher Scientific, Inc., Waltham, MA, USA) for $10 \mathrm{~min}$ at $37^{\circ} \mathrm{C}$ to remove traces of genomic DNA, and RNA quality and integrity were assessed by standard spectrophotometric and electrophoretic methods, respectively. A $10 \mathrm{ng}$ sample of total RNA was subject to reverse transcription-polymerase chain reaction (RT-PCR) using the SuperScript ${ }^{\circledR}$ III One-Step RT-PCR System with Platinum ${ }^{\circledR}$ Taq DNA Polymerase (Invitrogen; Thermo Fisher Scientific, Inc.). Previously reported consensus primers were selected to target segments of the NS5 coding region conserved across several FV species, including DENV-1, -2, -3 and -4 (9). The sequences of the primers are as follows: Flav100F (forward) 5'-AAYTCIACI CAIGARATGTAY-3' and Flav200R (reverse) 5'-CCIARC CACATRWACCA-3'. RT-PCR was performed as described previously (9). PCR products were cloned using the TOPO-XL cloning vector system using the PCR-XL-TOPO $3.5 \mathrm{~kb}$ kit (Invitrogen; Thermo Fisher Scientific, Inc.). The sequencing reactions of cloning products were performed with universal 
M13 primers using a Big Dye terminator v3.1 Cycle Sequencing kit (Applied Biosystems; Thermo Fisher Scientific, Inc.) in a 3100-Avant Genetic Analyzer sequencer (Applied Biosystems; Thermo Fisher Scientific, Inc.). The sequences of the M13 primers are as follows: Forward, 5'-CTGGCCGTCGTTTTA C-3' and reverse 5'-CAGGAAACAGCTATGAC-3'. Novel sequences were deposited in the GenBank database (accession no. MF073185-95; www.ncbi.nlm.nih.gov/Genbank/).

Bioinformatics analysis. The chromatograms and sequences obtained from three different clones from each PCR product were analyzed using the GeneStudio ${ }^{\mathrm{TM}}$ Pro v2.2.0.0. software (GeneStudio, Inc., Suwanee, GA, USA). By eliminating the sequences of the primers, $765 \mathrm{bp}$ nucleotide sequences were obtained and translated into 255 amino acids. Peptide sequences were predicted from obtained DNA sequences using the Transeq online program (www.ebi.ac.uk/emboss/transeq/) and aligned using ClustalW (www.ebi.ac.uk/Tools/msa/clustalo/) together with peptide sequences extracted from GenBank via homology search. Evolutionary history among the DENV-1 sequences were inferred through the construction of Minimum Spanning Networks utilizing the program PopArt v1.7 (Allan Wilson Centre, Otago, New Zealand). Once clades were identified their divergence was estimated by calculating the mean uncorrected $\mathrm{p}$-distance between them using the program MEGA v7.0 (10). The identified chimeras in both clades were modeled in the I-TASSER server (11) after being aligned with the NS5 RNA-dependent RNA polymerase domain [Protein Database (PDB_:2J7U A-chain)] (12) and inserted to complete the peptide sequence (chimera). Subsequently, models with the highest $\mathrm{C}$-score were evaluated in the MolProbity server (13-15). The conformational changes were computed in the web-interface elNemo (16) to identify sections susceptible to interact with other biomolecules.

Docking. The interaction of the chimeras of both clades was evaluated with the following receptors associated with the infectious process of DENV-1: Human type I interferon receptor (PDB:2HYM A) (17), Janus kinase 1 (JAK-1; PDB:3EYH) (18), plasma platelet activating factor acetylhidrolase (PDB:3D59 A,B) (19), unphosphorylated signal transducer and activator of transcription factor (STAT)-1 (PDB: 1YVL A) (20), platelet factor 4 (PDB: 1F9Q A,B,C.D) (21), interleukin-1 $\beta$ (2I1B) (22) and interleukin-6 (PDB: 1ALU) (23).

Preliminary docking was carried out with the receptors proposed by GRAMM-X Protein-Protein Docking Web Server v.1.2.0 $(24,25)$ in order to identify the most likely contact surfaces in both clades with these biological targets. Subsequently, the protein-protein in silico molecular coupling was performed on the server ClusPro 2.0 (Structural Bioinformatics Lab, Boston University, Boston, MA, USA) (26-28) masking only the amino acids corresponding to the base of human type I interferon receptor (PDB:2HYM A) and there were no further restrictions of attraction or repulsion on the other couplings.

In the analysis of the results, four aspects were evaluated to discriminate between the poses obtained: i) All analyzed complexes are products of balanced algorithms hydrophobic and electrostatically; ii) couplings were in accordance with the results of the conformational changes obtained in the web-interface ElNemo and similar to those obtained in the
GR AMM-X Protein-Protein Docking web server v.1.2.0; iii) they were equivalent in both clades for comparison purposes; and iv) priority was given to energy between protein centers (reported in Table II) to the lowest of the total complex.

Statistical analysis. Student's t-test was used to compare normally distributed mean values of the measurement variables. Qualitative data were compared using the chi-square test. The association between genetic variant (clades) and the risk for sever dengue was estimated by odds ratios (ORs) and $95 \%$ confidence intervals (CIs; crosstabs procedure). All statistical analyzes were performed using the SPSS statistical software, version 20 (IBM Corp., Armonk, NY, USA).

\section{Results}

Identification of patients with DENV. A total of 462 febrile patients were included in the present study, whose characteristics and initial clinical diagnosis are presented in Table I. Of the patients included, 31 were positive for FV. The obtained sequences in the present study corresponded to DENV-1, without finding another serotype of dengue, nor another FV. The sensitivity and specificity of the clinical diagnosis regarding the diagnosis of dengue fever were $58.06 \%$ (95\% CI, $39.08-77.05 \%)$ and $58 \%$ (95\% CI, 53.23-62.78\%), respectively. The positive predictive value was $9.05 \%$ (95\% CI, 4.81-13.28\%).

Analysis of NS5 sequences. A number of the 31 DENV sequences were identified, with 11 different patterns remaining. The evolutionary analysis revealed the presence of two groups with differences of $1.3 \%$ (standard error $\pm 0.04 \%$ ) in their nucleotide sequences as indicated in the minimum spanning network of Fig. 1.

Of the nucleotide differences between the clades, only two generated amino acid changes in the NS5 protein. Considering the nucleotide sequence of GenBank KJ651911.1 of the NS5 gene, these variations are $372 \mathrm{~A} / \mathrm{G}$ and $496 \mathrm{G} / \mathrm{A}$. Referring to the GenBank protein sequence AJL35015.1, the variations are at position $124 \mathrm{Ile} / \mathrm{Met}$ and $166 \mathrm{Gly} / \mathrm{Ser}$, in clade $1 / 2$, respectively. These positions are equivalent to $8593 / 8717$ of the viral genome and positions 2833/2875 of the viral polyprotein.

Dividing the patients with dengue according to the virus clade, there were 16 patients with clade 1 and 15 with clade 2 . Epidemiologically, it was found that clade 1 (Fig. 1) was the first to appear during 2007 and was located almost exclusively on the warm coastal region of Colima (Municipalities of Manzanillo and Tecoman). Clade 2 viruses (Fig. 1) were observed at the end of 2008, predominantly in the higher and temperate areas of the state (Municipalities of Colima, Villa de Álvarez and Cuahutemoc). Regarding the clinical behavior of the 16 patients with clade 1 virus, only 1 progressed to severe dengue that required hospitalization for 3 days, with a clinical diagnosis of hemorrhagic dengue. Of the 15 patients corresponding to clade 2, 5 had severe dengue with the following clinical diagnoses: 2 patients with hemorrhagic dengue, 1 with hepatitis/pneumonitis, 1 with viral hepatitis and 1 with probable rickettsiosis. The patient with probable rickettsiosis succumbed to mortality. These patients had a mean hospital stay of 5.3 days. Infection with clade 2 virus significantly increased the risk of having severe dengue 10-fold (OR, 10; 
Table I. Description of febrile population analyzed.

\begin{tabular}{|c|c|}
\hline Variable & Patients (n) \\
\hline \multicolumn{2}{|l|}{ Sex } \\
\hline Female & 234 \\
\hline Male & 228 \\
\hline \multicolumn{2}{|l|}{ Age (years) } \\
\hline $6-20$ & 232 \\
\hline $21-40$ & 144 \\
\hline $41-60$ & 65 \\
\hline $60-80$ & 21 \\
\hline \multicolumn{2}{|l|}{ Community } \\
\hline Urban & 411 \\
\hline Rural & 51 \\
\hline \multicolumn{2}{|l|}{ Zone } \\
\hline Coastal & 307 \\
\hline Non-coastal & 155 \\
\hline \multicolumn{2}{|l|}{ Initial diagnosis } \\
\hline Unspecific fever & 180 \\
\hline Dengue & 201 \\
\hline Respiratory Infection & 14 \\
\hline Influenza & 12 \\
\hline Tonsilitis & 9 \\
\hline Rhinopharyngitis & 7 \\
\hline Meningitis & 7 \\
\hline Pharyngotonsillitis & 6 \\
\hline Urosepsis & 4 \\
\hline Urinary infection & 4 \\
\hline Hepatitis & 3 \\
\hline Pneumonia & 2 \\
\hline Typhoid & 2 \\
\hline Dysentery syndrome & 1 \\
\hline Ricketsiosis & 1 \\
\hline Acute pyelonephritis & 1 \\
\hline Rheumatic fever & 1 \\
\hline Typhoid & 1 \\
\hline Encephalitis & 2 \\
\hline Parasitosis & 1 \\
\hline Anemia & 1 \\
\hline Tonsillitis & 2 \\
\hline
\end{tabular}

95\% CI, 1.03-97.04; $\mathrm{P}=0.03$ ), determined by a crude analysis without considering other host factors.

Given this association of a clade with the severity of the disease, an in silico analysis was performed to determine the effects on the NS5 protein of the two amino acid variations that mark the difference between the two clades. For this, a modeling of the NS5 protein was initially performed and a docking methodology was subsequently used to determine its interaction with other proteins previously implicated in the pathophysiology of similar infections.

Modeling of NS5 clade 1 and 2. The chimeras corresponding to clade 1 and 2 were analyzed. It was demonstrated that

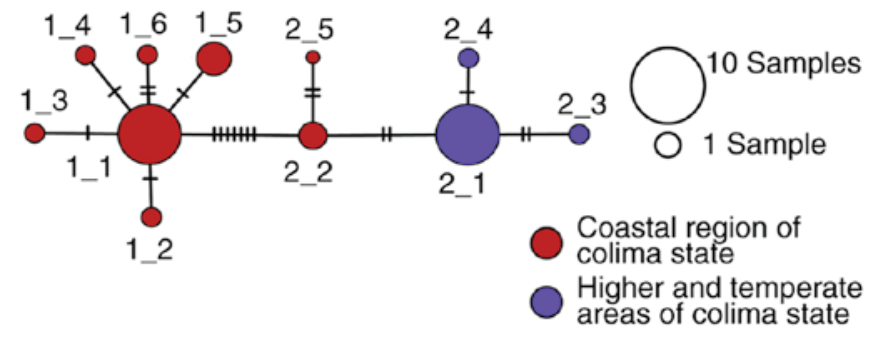

Figure 1. Minimum spanning network among the isolates. Two main clades were observed (clade 1 and 2). Circles sizes are proportional to the number of sequences that exhibit each variant. Connecting lines indicate a single mutation among variants.

residues that are different between clade 1 and 2 are located in critical regions, as amino acid 166 and neighbors form part of an alpha helix that serves an important role in the interaction between NS5 and other proteins.

Docking. The present results (Table II) suggest that clade 2 had a greater attraction with human type I interferon receptor and JAK-1, which was also demonstrated by the three-dimensional representations of Fig. 2.

The greatest difference in affinities between the two NS5s with the other proteins was observed in the coupling with JAK-1, with a difference of $-101 \mathrm{kcal} / \mathrm{mol}$ in favor of clade 2 . In order to identify which of the two amino acids changes of this clade had more relevance in these couplings, new chimeric NS5s were generated where a single amino acid was changed with respect to clade 1 . These new chimeras had the following variations: 124Ile and 166Ser; or 124Met and 166Gly. The Ile/Ser variant had energies of -690.4 and $-660.4 \mathrm{kcal} / \mathrm{mol}$, whereas the variant Met/Gly had energies of -781.2 and $-656.6 \mathrm{kcal} / \mathrm{mol}$, for the JAK-1 and interferon receptor 1 , respectively. Taking as reference the composition of clade 1 (Ile/Gly), which exhibited energies of coupling of JAK-1 and interferon receptor 1 of -702.2 and $-650.2 \mathrm{kcal} / \mathrm{mol}$, respectively, it may be inferred that the greater affinity of clade 2 with JAK-1 depends mostly on the amino acid 124Met, whereas its greater affinity with the interferon receptor does not depend mainly on some of the analyzed amino acids.

\section{Discussion}

The findings of the present study suggest that during an epidemic caused by DENV-1, the clinical behavior may be associated with genetic variants of the virus, independently to the presence of other risk factors. This result was relevant, as it had recently been estimated that in some regions of the world, among the 4 DENV serotypes, DENV-1 exhibits the highest risk of severe disease (29). A viral variant reported in the present study, called clade 2 , generated a 10 -fold increased risk of severe infection. The difference associated with severe disease was given only by two amino acid changes in NS5, whereas residues Met124 and Ser166 in clade 2 replaced the Ile and Gly of clade 1, respectively. Previously it had been demonstrated that subtle sequence changes in viral proteins may generate alterations in their biological behavior. For example, in studies performed by Zulkarnain et al (30) and Ishak et al (31) based on the comparison of the amino acid 
Table II. Coupling energies in the center of clade 1 and 2 with possible NS5 receptor RNA-dependent RNA polymerase.

\begin{tabular}{lcc}
\hline Receptor PDB & Complex clade 2 (cal/mol) & Complex clade 1 (kcal/mol) \\
\hline Janus kinase-1 (3EYH) & -818.7 & -702.2 \\
Type I interferon receptor (2HYM A) & -663.1 & -650.2 \\
PPAFA (3D59 A,B) & -884.1 & -877.0 \\
Interleukin-6 (1ALU) & -765.8 & -764.1 \\
Unphosphorylated STAT1 (1YVLA) & -800.7 & -801.2 \\
Platelet FACTOR 4 (1F9Q A,B,C.D) & -710.1 & -714.3 \\
Interleukin-1 $\beta$ (2I1B) & -650.6 & -654.6
\end{tabular}

PDB, protein database; PPAFA, plasma platelet activating factor acetylhidrolase; STAT1, signal transducer and activation of transcription factor-1.

A
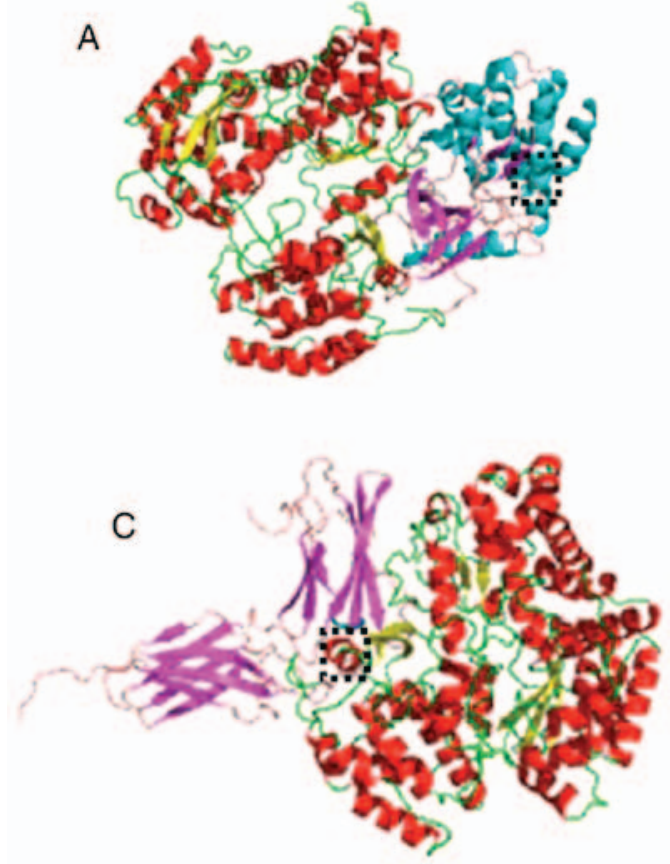

B
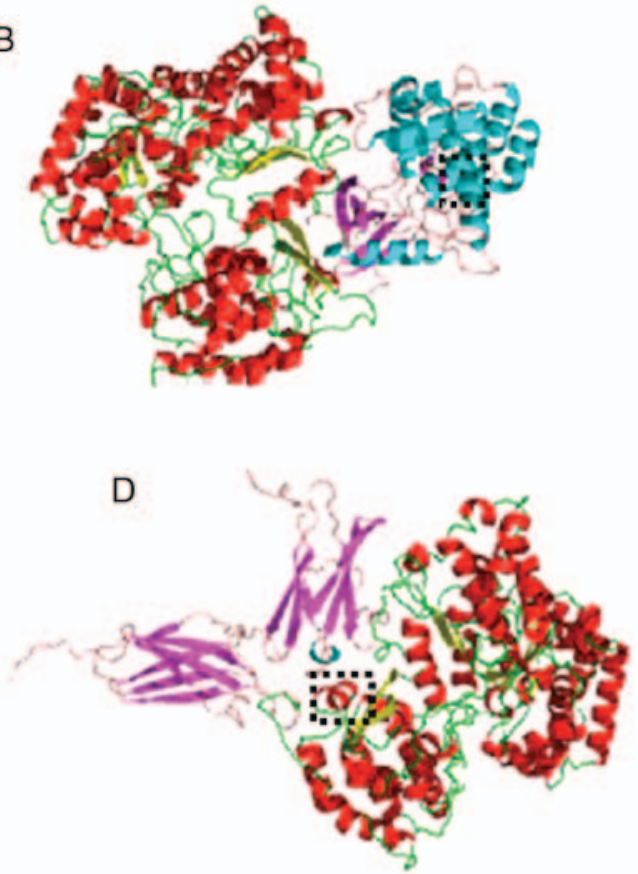

Figure 2. Protein-protein coupling of the NS5 chimeras corresponding to clade 1 and 2 (red, yellow). (A) Clade-2 and JAK-1 complex (blue and violet). (B) Clade 1 and JAK-1 complex. (C) Clade 2 and type I interferon receptor complex (violet). (D) Clade 1 and type I interferon receptor complex. In the dotted box, residue 166 is located and neighbors according to the numbering of the reference protein sequence (GenBank accession ID, AJL35015.1; Ser in clade 2 and Gly in clade 1). JAK, Janus kinase.

and nucleotide sequences in dengue type 1 protein E, NS3, NS4A and NS5. The change of few amino acid residues may modify the replication characteristics of the virus in in vitro experiments. In particular, in the NS5 RNA-dependent RNA polymerase, there are amino acids that are critical for some of their functions. Studies of this protein from other flaviviruses, such as Langat (32) and West Nile Virus NY99 (33), have demonstrated that some residues $(623,635,641,643$ and 653) are important for the protein to serve a role as an antagonist of type I interferon $(\alpha / \beta)$, and suppressing the JAK-STAT signaling pathway.

In the present study, it was demonstrated that changes in NS5 may generate changes in the protein structure with possible implications in their interactions, though in silico tests. The amino acid at position 166 and neighboring residues are part of an $\alpha$ helix that serves an important role in the interaction between NS5 and other host proteins according to in silico couplings. This $\alpha$ helix is preferably located in the center of the most probable pose of coupling, which infers that it is a critical region in the NS5. When comparing the coupling energies, no difference $>7 \mathrm{kcal} / \mathrm{mol}$ was observed between clades in the complexes with interleukins, STAT1 and with the plasma platelet activating factor, thus it was assumed that the clinical differences associated with the viral variants are not associated with variations in the interaction with these proteins. However, the interaction difference of the two NS5 variant (clade 1 vs. 2) with the interferon type 1 receptor was appreciable $(13.1 \mathrm{kcal})$. The closest approach in clade 2 of the critical area of residue 166 of the NS5 with the center of the receiver was visible. This may mean that NS5 clade 2 is a more efficient antagonist of type 1 interferon by interfering with its receptor. 
However, the most important difference was in the coupling with JAK-1, being - $101 \mathrm{kcal} / \mathrm{mol}$ in favor of clade 2, and in which a greater number of residues participate and allow a better penetration. This suggests that genetic variants $372 \mathrm{~A} / \mathrm{G}$ and 496G/A (protein variants 124Ile/Met and 166Gly/Ser) in NS5 of DENV-1 condition the degree of antagonism with type 1 interferon due to interruption of JAK-STAT1. It has recently been reported, in similar viruses, that replication increases through inhibiting the JAK-STAT signaling pathway (34).

It has also been evidenced that the JAK/STAT3 pathway is critical in chemokine production from DV-infected hepatocytes. The response of interferon or cytokines to dengue infection was part of the innate immunity initiated at day $0-1$ following DENV infection, and declines 3-4 days thereafter. The upregulation of these early innate immune responses coincides, as it should from an immune surveillance perspective, with a drop in DENV viral replication during days 0-3 of the fever (35). A variation in the impairment of the function of type 1 interferon, either at the level of its receptor or by interfering with its signaling pathway (JAK-STAT) may cause variations in the clinical course of the disease. A better coupling of the NS5 variant of clade 2 with the interferon 1 receptor and with JAK-1 may cause the association found in the present study, between this genetic variant of dengue with a more severe clinical course. Interestingly, none of the patients presented a simultaneous infection among the identified DENV1 strains; therefore, dengue disease progression remains unknown when both NS5 genetic variations are present in those patients. Thus, the biological interactions of DENV-1 NS5 need to be tested experimentally in future studies.

It was observed that for coupling with JAK-1, the most relevant amino acid was $124 \mathrm{Met}$. This variation in DENV-1 has only previously been reported in two samples from Singapore and Cambodia (ABW82089.1 and ACL99206.1, respectively) recollected in 2005 and 2007 (28). This was relevant, as a report by Yung et al (29), which analyzed the cases of dengue in Singapore from 2005-2011, demonstrated that among the four serotypes of the virus, DENV-1 had the highest risk of severe disease. This may be due to the presence of this viral variant in the analyzed epidemic outbreaks of Singapore. In other regions of the world, DENV-2 and -3 were the most associated with severe disease $(36,37)$. The amino acid $166 \mathrm{Ser}$ is not the most common residue in DENV-1 and has been previously reported in only three sequences from Argentina, Puerto Rico and Thailand in samples from 2009, 2010 and 2011, respectively (GenBank: AHF50483.1, AHI43747.1 and AKL88404.1) (36). However, they have not previously reported a sequence with the two changes that were identified in the present study in clade 2 (124Met and 166GSer). It is notable that the residue $124 \mathrm{Met}$ was commonly reported in homologous sequences of DENV-2 (example GenBank: AOE23003.1) and DENV-3 (example GenBank: ANS59201.1). Therefore, it may be interesting to know if the amino acid equivalent to 124Met of the NS5 in DENV-2 and -3 has an important effect in the interaction with JAK-1.

A limitation of the present study is the fact that an analysis to corroborate the present docking observations at the molecular level was not performed. Ongoing experimental studies at our laboratory are being performed to explore the key role of interferon- $\alpha / \beta$ in the JAK-STAT signaling pathway.
An important epidemiological aspect was that during a similar epidemic outbreak caused by a same serotype of dengue in our region, there were genetic, geographic and clinical variations over time (data not shown). Clade 2 (associated with severity) occurred one year after the onset of the outbreak in higher altitudes, cooler temperatures, and more severe forms of the disease, including a mortality due to multiple organ failure, which was clinically confused with a rickettsiosis. It is difficult to establish whether a genetic variant of DENV-1 was introduced from another region at the end of the epidemic outbreak and replaced the previous variant; or if it was a de novo mutation in the course of the epidemic outbreak that generated the new variant. It has recently been suggested that a rapid pattern of mutations in DENV-1 is possible within an epidemic (evolutionary process in situ). Although an epidemic outbreak of dengue is maintained over time with the same virus serotype, it does not imply that it is necessarily the same virus from the genetic and pathogenic point of view.

In conclusion, the genetic variants $372 \mathrm{G}$ and 496A of NS5 from DENV-1 were associated with a severe clinical course of the disease in an epidemic outbreak in a region of Mexico. The variations generate changes in the protein that probably most effectively block the innate immune response, by affecting the function of type 1 interferon, either at the level of its receptor or by interfering with its JAK-STAT signaling pathway. Biological testing and studies in other populations are necessary.

\section{Acknowledgements}

The present study was completed using equipment resources obtained through grants from the INFRAESTRUCTURACONACYT (grant no. 270485), FOSISS-CONACYT (grant no. 272792) and FORDECyT-CONACYT (grant no. 2009/1-000000117535).

\section{Competing interests}

The authors declare that they have no competing interests.

\section{References}

1. Gubler DJ: Dengue and dengue hemorrhagic fever. Clin Microbiol Rev 11: 480-496, 1998.

2. Kuno G, Chang GJ, Tsuchiya KR, Karabatsos N and Cropp CB: Phylogeny of the genus Flavivirus. J Virol 72: 73-83, 1998.

3. Leitmeyer KC, Vaughn DW, Watts DM, Salas R, Villalobos I, Ramos C and Rico-Hesse R: Dengue virus structural differences that correlate with pathogenesis. J Virol 73: 4738-4747, 1999.

4. Descloux E, Cao-Lormeau VM, Roche C and De Lamballerie X: Dengue 1 diversity and microevolution, French Polynesia 2001-2006: Connection with epidemiology and clinics. PLoS Negl Trop Dis 3: e493, 2009.

5. Halstead SB: Dengue in the Americas and Southeast Asia: Do they differ? Rev Panam Salud Publica 20: 407-415, 2006.

6. Rico-Hesse R, Harrison LM, Salas RA, Tovar D, Nisalak A, Ramos C, Boshell J, de Mesa MT, Nogueira RM and da Rosa AT: Origins of dengue type 2 viruses associated with increased pathogenicity in the Americas. Virology 230: 244-251, 1997.

7. Diamond MS: Evasion of innate and adaptive immunity by flaviviruses. Immunol Cell Biol 81:196-206, 2003.

8. Hapuarachchi HC, Koo C, Kek R, Xu H, Lai YL, Liu L, Kok SY, Shi Y, Chuen RL, Lee KS, et al: Intra-epidemic evolutionary dynamics of a Dengue virus type 1 population reveal mutant spectra that correlate with disease transmission. Sci Rep 6: 22592, 2016.

9. Maher-Sturgess SL, Forrester NL, Wayper PJ, Gould EA, Hall RA, Barnard RT and Gibbs MJ: Universal primers that amplify RNA from all three flavivirus subgroups. Virol J 5: 16, 2008. 
10. Kumar S, Stecher G and Tamura K: MEGA7: Molecular evolutionary genetics analysis version 7.0 for bigger datasets. Mol Biol Evol 33: 1870-1874, 2016.

11. Roy A, Kucukural A and Zhang Y: I-TASSER: A unified platform for automated protein structure and function prediction. Nat Protoc 5: 725-738, 2010.

12. Yap TL, Xu T, Chen YL, Malet H, Egloff MP, Canard B, Vasudevan SG and Lescar J: Crystal structure of the dengue virus RNA-dependent RNA polymerase catalytic domain at 1.85-angstrom resolution. J Virol 81: 4753-4765, 2007.

13. Davis IW, Leaver-Fay A, Chen VB, Block JN, Kapral GJ, Wang X, Murray LW, Arendall WB III, Snoeyink J, Richardson JS and Richardson DC: MolProbity: All-atom contacts and structure validation for proteins and nucleic acids. Nucleic Acids Res 35: W375-W383, 2007.

14. Chen VB, Arendall WB III, Headd JJ,Keedy DA, Immormino RM, Kapral GJ, Murray LW, Richardson JS and Richardson DC: MolProbity: All-atom structure validation for macromolecular crystallography. Acta Crystallogr D Biol Crystallogr 66: 12-21, 2010.

15. Chen VB, Davis IW and Richardson DC: KING (Kinemage, Next Generation): A versatile interactive molecular and scientific visualization program. Protein Sci 18: 2403-2409, 2009.

16. Suhre K and Sanejouand YH: On the potential of normal-mode analysis for solving difficult molecular-replacement problems. Acta Crystallogr D Biol Crystallogr 60: 796-799, 2004.

17. Quadt-Akabayov SR, Chill JH, Levy R, Kessler N and Anglister J: Determination of the human type I interferon receptor binding site on human interferon-alpha2 by cross saturation and an NMR-based model of the complex. Protein Sci 15: 2656-2668, 2006.

18. Williams NK, Bamert RS, Patel O, Wang C, Walden PM, Wilks AF, Fantino E, Rossjohn J and Lucet IS: Dissecting specificity in the Janus kinases: The structures of JAK-specific inhibitors complexed to the JAK 1 and JAK2 protein tyrosine kinase domains. J Mol Biol 387: 219-232, 2009.

19. Samanta U and Bahnson BJ: Crystal structure of human plasma platelet-activating factor acetylhydrolase: Structural implication to lipoprotein binding and catalysis. J Biol Chem 283: 31617-31624, 2008.

20. Mao X, Ren Z, Parker GN, Sondermann H, Pastorello MA, Wang W, McMurray JS, Demeler B, Darnell JE Jr and Chen X: Structural bases of unphosphorylated STAT1 association and receptor binding. Mol Cell 17: 761-771, 2005.

21. Yang J, Doyle M, Faulk T, Visentin G, Aster R and Edwards B Crystal structure of platelet factor 4 mutant 2: Full wwPDB X-ray Structure Validation Report. Sept 27, 2017. http://files.rcsb. $\mathrm{org} / \mathrm{pub} / \mathrm{pdb} / \mathrm{validation}$ reports/f9/1f9q/1f9q_full_validation.pdf.

22. Priestle JP, Schär HP and Grütter MG: Crystallographic refinement of interleukin 1 beta at 2.0 A resolution. Proc Nat Acad Sci USA 86: 9667-9671, 1989.

23. Somers W, Stahl M and Seehra JS: 1.9 A crystal structure of interleukin 6: Implications for a novel mode of receptor dimerization and signaling. EMBO J 16: 989-997, 1997.

24. Tovchigrechko A and Vakser IA: GRAMM-X public web server for protein-protein docking. Nucleic Acids Res 34: W310-W314, 2006.
25. Tovchigrechko A and Vakser IA: Development and testing of an automated approach to protein docking. Proteins 60: 296-301, 2005.

26. Kozakov D, Hall DR, Beglov D, Brenke R, Comeau SR, Shen Y, Li K, Zheng J, Vakili P, Paschalidis ICh and Vajda S: Achieving reliability and high accuracy in automated protein docking: Cluspro, PIPER, SDU, and stability analysis in CAPRI rounds 13-19. Proteins 78: 3124-3130, 2010.

27. Kozakov D, Brenke R, Comeau SR and Vajda S: PIPER: An FFT-based protein docking program with pairwise potentials. Proteins 65: 392-406, 2006

28. Comeau SR, Gatchell DW, Vajda S and Camacho CJ: ClusPro: An automated docking and discrimination method for the prediction of protein complexes. Bioinformatics 20: 45-50, 2004.

29. Yung CF, Lee KS, Thein TL, Tan LK, Gan VC, Wong JG, Lye DC, $\mathrm{Ng}$ LC and Leo YS: Dengue serotype-specific differences in clinical manifestation, laboratory parameters and risk of severe disease in adults, Singapore. Am J Trop Med Hyg 92: 999-1005, 2015.

30. Zulkarnain E, Hotta S and Takegami T: Molecular comparison of dengue type 1 Mochizuki strain virus and other selected viruses concerning nucleotide and amino acid sequences of genomic RNA: A consideration of viral epidemiology and variation. Microbiol Immunol 38: 581-585, 1994.

31. Ishak H, Takegami T, Kamimura K and Funada H: Comparative sequences of two type 1 dengue virus strains possessing different growth characteristics in vitro. Microbiol Immunol 45: 327-331, 2001.

32. Park GS, Morris KL, Hallett RG, Bloom ME and Best SM: Identification of residues critical for the interferon antagonist function of Langat virus NS5 reveals a role for the RNA-dependent RNA polymerase domain. J Virol 81: 6936-6946, 2007.

33. Laurent-Rolle M, Boer EF, Lubick KJ, Wolfinbarger JB, Carmody AB, Rockx B, Ashour J, Shupert WL, Holbrook MR, Barrett $\mathrm{AD}$, et al: The NS5 protein of the virulent West Nile virus NY99 strain is a potent antagonist of type I interferon-mediated JAK-STAT signaling. J Virol 84: 3503-3515, 2010.

34. Wang J, Chen S, Liao Y, Zhang E, Feng S, Yu S, Li LF, He WR, Li Y, Luo Y, et al: Mitogen-Activated Protein Kinase Kinase 2, a Novel E2-interacting protein, promotes the growth of classical swine fever virus via attenuation of the JAK-STAT signaling pathway. J Virol 90: 10271-10283, 2016.

35. Chiappelli F, Santos SM, Caldeira Brant XM, Bakhordarian A, Thames AD, Maida CA, Du AM, Jan AL, Nahcivan M, Nguyen MT and Sama N: Viral immune evasion in dengue: Toward evidence-based revisions of clinical practice guidelines. Bioinformation 10: 726-733, 2014.

36. Díaz FJ, Black WC IV, Farfán-Ale JA, Loroño-Pino MA, Olson KE and Beaty BJ: Dengue virus circulation and evolution in Mexico: A phylogenetic perspective. Arch Med Res 37: 760-773, 2006.

37. Espinoza-Gómez F, López-Lemus AU, Rodriguez-Sanchez IP, Martinez-Fierro ML, Newton-Sánchez OA, Chávez-Flores E and Delgado-Enciso I: Detection of sequences from a potentially novel strain of cell fusing agent virus in Mexican Stegomyia (Aedes) aegypti mosquitoes. Arch Virol 156: 1263-1267, 2011. 